\title{
A Two Years Study on Pregnant Women with Cardiac Disease in a Tertiary Care Centre
}

\author{
SYEDA SAYEEDA ${ }^{1}$, FATIMA WAHID ${ }^{2}$, FIROZA BEGUM ${ }^{3}$, MAHBOOB MUSTAFA ZAMAN $^{4}$
}

\begin{abstract}
:
Objective: To analyse the pregnant women with heart disease and to assess its influence on the fetomaternal outcome.

Materials and methods: This observational study was carried out during the period from Jan 2006 to Sept 2007. Fifty pregnant women with cardiac diseases who were admitted in the Fetomaternal Medicine unit of the department of Obstetrics \& Gynaecology in Bangabandhu Sheikh Mujib Medical University (BSMMU) were included in the study.

Results: Rheumatic heart disease ( $n-37,74 \%)$ with isolated mitral stenosis (28\%) was the predominant cardiac problem among the study subjects while atrial septal defect (16\%) was the most common form of congenital heart disease (n-13, 26\%). Based on New York Heart Association (NYHA) functional classification, 40(80\%) women were in class-I, 7(14\%) were in class-II and 3(6\%) were in class-III heart disease on presentation. The mean ( \pm SD) gestational age at delivery was $37.50( \pm 2.50)$ weeks and pregnancy duration was shortened in more advanced classes of heart disease. The rate of cesarean section (90\%) was high in the study subjects. The rate of prematurity (55.5\%) was high among class II and III and average birth weight of neonates were less among these two classes compared to class I $(2.80 \pm 0.20 \mathrm{~kg}$ in Class-I, $2.30 \pm 0.26$ in Class-II and 2.10 \pm 0.34 in Class-III). No baby was delivered stillborn and there was no neonatal death. Out of fifty, nine patients developed heart failure during the hospital

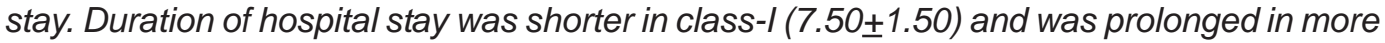

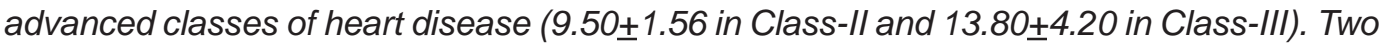
patients of the study subjects expired.
\end{abstract}

Conclusion: Rheumatic heart disease was the predominant type of heart disease in pregnancy and most of the women were in class I on admission. The neonatal outcome was satisfactory. Two patients in the congenital heart disease group expired during the study period.

Key words: Maternal, Fetal, Cardiac disease.

\section{Introduction:}

Pregnancy causes dramatic, usually reversible change in a woman's cardiovascular system. Cardiovascular disease is the most important non-obstetric cause of disability and death in pregnant woman occurring in 0.4 to 4.0 percent pregnancies. ${ }^{1}$ The reported maternal mortality rate ranges from 0.4 percent in patients with New York Heart Association (NYHA) classification I and II to 6.8 percent or higher among patients with classification III and IV severity. It is not surprising that added haemodynamic burden of pregnancy, labor and delivery can aggravate symptoms and precipitate complications in a woman with preexisting cardiac disease.

Heart disease can be classified as congenital or acquired. Acquired diseases can be infectious, autoimmune, degenerative and idiopathic. ${ }^{1}$ Heart disease has a significant impact on fetal and maternal health during pregnancy, labor and delivery. The main problems encountered in a pregnant woman with heart disease arise from complications of already existing chronic disorders like rheumatic and congenital heart lesions and hypertensive cardiovascular disease. ${ }^{2}$

1. Assistant Professor, Dept of OBS \& GYNAE, BSMMU, Dhaka

2. Medical Officer, Dept of OBS \& GYNAE, BSMMU, Dhaka

3. Professor\& Head, Fetomaternal medicine, Dept of OBS \& GYNAE, BSMMU, Dhaka

4. Student, FCPS Part-II (Medicine) BSMMU, Dhaka 
The commonest cardiac lesion during pregnancy is of rheumatic origin followed by congenital one. ${ }^{3}$ The prevalence of pregnancy with rheumatic heart disease has decreased in developed countries in last two decades. The former ratio of 3:1 for rheumatic to congenital heart disease in series of pregnant woman with cardiac disease is now reversed. Rheumatic heart disease is still the leading cause of death due to heart disease in young woman in the developing world. ${ }^{4}$

The most dominant rheumatic lesions have been mitral stenosis (80\%), followed by aortic stenosis (10\%), mitral regurgitation (6.6\%) and aortic regurgitation $(2.5 \%) .^{2}$ The improvement in cardiovascular surgery has improved the prognosis of congenital lesions and many women even with severe defects are now reaching the child bearing age.

Mortality due to heart disease can be preventable and is largely dependent on timely interference. ${ }^{5}$ Pregnant woman with valvular heart disease should be managed by high risk obstetric service which provides cardiology consultation, close obstetric supervision and provision of delivery with haemodynamic monitoring when required. Ideally the patient with known heart disease should consult her physician before becoming pregnant. If a woman with heart disease presents for medical care after she has become pregnant, the obstetrician must be able to recognize the presence of preexisting cardiac disease, asses the degree of disability and understand the impact of the added haemodynamic changes of pregnancy. A team should carry out management of an obstetric patient with heart disease consisting of an obstetrician, cardiologist and anesthesiologist. ${ }^{1}$

A study conducted in University of South Carolina USA in 2001, found that pregnant women with valvular heart disease had a significantly higher incidence of congestive heart failure, arrhythmia, initiation and increase of cardiac medication and hospitalization. ${ }^{6}$ Valvular and congenital heart disease had an effect on fetal outcome resulting in an increased preterm delivery, intrauterine growth retardation and low birth weight. Increased maternal morbidity and unfavorable fetal outcome were seen mostly in patients with moderate and severe mitral stenosis and aortic stenosis. ${ }^{7}$

The purpose of this study was to analyse the pregnant women with heart disease and thereby to assess the influence of cardiac disease on pregnancy and delivery in terms of maternal and fetal outcome.

\section{Materials and Methods:}

This observational study was carried out from January 2006 to September 2007 in the department of Obstetrics \& Gynaecology, BSMMU. Fifty consecutive patients with heart diseases either booked or nonbooked cases, who were admitted in the feto-maternal medicine unit of BSMMU during the study period, were recruited. The booked cases were seen by obstetrician in the feto-maternal medicine out patient department (OPD) and by cardiologist in the respective OPD to check for their cardiac status. The non-booked cases were referred from different hospitals or clinics or other obstetricians when some critical conditions developed. One of such patient was who remained undiagnosed of her rheumatic heart disease throughout her antenatal check up (ANC) but referred by her obstetrician when she developed respiratory distress at her 34 weeks of pregnancy. After having informed consent, the pregnant patients with rheumatic heart diseases and with congenital heart diseases were included in the study while the patients having heart diseases with other medical disorders were excluded.

After admission, the patients were classified according to the type of heart disease, either congenital or acquired, from the history obtained from the patients, from their attendants as well as from the previous medical records. Grading of the heart disease was done according to the criteria of New York Heart Association (NYHA) functional classification. For the confirmation of diagnosis and also for the management purpose, patients were evaluated by both cardiologists and obstetricians regularly and investigations including ECG and Echocardiography were done in all cases. Gestational age of the women were calculated from the last menstrual period, clinical examination and ultrasonography report. Fetal conditions were assessed by clinical examination, cardiotocography, ultrasonography and biophysical profile. The mode of delivery was decided on the basis of the condition of the mother as well as fetal condition. In most of the cases, the mode of delivery was elective cesarean section and the patients were evaluated by both cardiologist and anaesthesiologist during the pre, post and intraoperative management. A senior anaesthesiologist used to be present in the operation theatre during the procedure. Those patients, who went into labour spontaneously, were allowed to deliver vaginally if there were otherwise no obstetric indication for cesarean section. However, they were also evaluated by cardiologist for there cardiac status. 
Immediately after delivery APGAR score and birth weight of the babies were noted. All the neonates were seen by neonatologists to exclude any congenital heart defects specially in women with congenital heart disease. All the information was gathered in a prepared data sheet.

\section{Results:}

The mean $( \pm S D)$ age of the patients was $27.00( \pm 4.2)$ years (ranging from 18-35years), most (82\%) belonged to age group18-30 years and nine (18\%) belonged to $>30$ years age group. Regarding parity and gravidity, highest number of patients (64\%) belonged to nulliparous group and most of the patients (46\%) were primigravida. Out of 50 patients, forty one (82\%) women received regular antenatal care while nine (18\%) women were on irregular antenatal care (Table- I).

Table-I

Characteristics of the study subjects $(n=50)$

\begin{tabular}{lc}
\hline Parameters & Mean \pm SD/Frequency \\
\hline Maternal age (years) & $27.00 \pm 4.2$ \\
$18-30$ & $41(82 \%)$ \\
$>30$ & $9(18 \%)$ \\
Parity & \\
0 & $32(64 \%)$ \\
1 & $11(22 \%)$ \\
2 & $6(12 \%)$ \\
3 or more & $1(2 \%)$ \\
gravidity & \\
1 & \\
2 & $23(46 \%)$ \\
3 & $16(32 \%)$ \\
4 or more & $6(12 \%)$ \\
Antenatal care & $5(10 \%)$ \\
Regular & \\
Irregular & \\
\hline
\end{tabular}

Table- II shows that thirty seven (74\%) women were suffering from rheumatic heart disease and in the rheumatic heart disease group $28 \%$ had isolated mitral stenosis. Twenty two (44\%) had mitral stenosis with other valvular disease. Only one (2\%) woman had isolated aortic stenosis. Thirteen (26\%) women were suffering from congenital heart disease, where Atrial septal defect was the most common form (16\%).
Among the study patients, thirteen (26\%) women had history of cardiac surgery prior to the present pregnancy and thirty seven (74\%) women had no such history (Table-III). The types of cardiac surgery were Closed Mitral Commisurotomy (14\%), repair of ASD (6\%), repair of VSD (2\%), repair of Left to Right Shunt (LR shunt 2\%) and Percutaneus trans-septal mitral commisurotomy (PTMC 2\%).

Table-II

Type of heart disease $(n=50)$

\begin{tabular}{|c|c|c|}
\hline Diagnosis & er of patients & Percentage \\
\hline Rheumatic & 37 & 74 \\
\hline Mitral stenosis & 14 & 28 \\
\hline Mitral regurgitation & 7 & 14 \\
\hline $\begin{array}{l}\text { Mitral stenosis + mitral } \\
\text { regurgitation }\end{array}$ & 5 & 10 \\
\hline Aortic stenosis & 1 & 2 \\
\hline $\begin{array}{l}\text { Mitral stenosis + aortic } \\
\text { regurgitation }\end{array}$ & 1 & 2 \\
\hline $\begin{array}{l}\text { Mitral stenosis + Mitral } \\
\text { regurgitation + aortic } \\
\text { regurgitation }\end{array}$ & 3 & 6 \\
\hline $\begin{array}{l}\text { Mitral stenosis + aortic } \\
\text { regurgitation+ pulmonary } \\
\text { hypertension }\end{array}$ & 1 & 2 \\
\hline $\begin{array}{l}\text { Mitral stenosis }+ \\
\text { pulmonary hypertension }\end{array}$ & 3 & 6 \\
\hline $\begin{array}{l}\text { Mitral stenosis + mitral } \\
\text { regurgitation+ } \\
\text { pulmonary hypertension+ } \\
\text { congestive cardiac failure }\end{array}$ & 1 & 2 \\
\hline $\begin{array}{l}\text { Mitral stenosis + mitral } \\
\text { regurgitation+ } \\
\text { aortic regurgitation+ } \\
\text { tricuspid regurgitation+ } \\
\text { pulmonary hypertension }\end{array}$ & 1 & 2 \\
\hline Congenital & 13 & 26 \\
\hline Atrial septal defect & 8 & 16 \\
\hline Ventricular septal defect & 3 & 6 \\
\hline TOF & 1 & 2 \\
\hline ASD + VSD+ PHTN & 1 & 2 \\
\hline
\end{tabular}

Regarding classification of heart disease, forty (80\%) women belonged to class I, seven (14\%) women belonged to class II and three (6\%) women belonged to class III heart disease according to NYHA classification. None of the patients belonged to class IV on admission (Table- IV). 
Table-III

History of cardiac surgery prior to pregnancy $(n-=50)$

\begin{tabular}{lcc}
\hline $\begin{array}{l}\text { History of } \\
\text { cardiac surgery }\end{array}$ & Number of patients & Percentage \\
\hline Present & 13 & 26 \\
Absent & 37 & 74 \\
\hline
\end{tabular}

Table- IV

Distribution of the patients ( $n=50)$ according to NYHA class on Presentation

\begin{tabular}{lcc}
\hline NYHA class & No of patients & (percentage) \\
\hline Class I & 40 & $(80)$ \\
Class II & 07 & $(14)$ \\
Class III & 03 & $(06)$ \\
Class IV & 00 & $(00)$ \\
\hline
\end{tabular}

Of fifty women, 49 patients delivered, while only one patient of class II, who was admitted at her 34 weeks of gestation with severe mitral stenosis with pulmonary hypertension, was treated conservatively and was discharged with advice for PTMC. The mean $( \pm S D)$ gestational age of the mothers at delivery was $37.50( \pm 2.50)$ weeks (ranging from 33 to 40 ) while most women (55.1\%) delivered between 37-38 weeks (Table-V).

\section{Table-V}

Gestational age of the women $(n=49)$ at delivery

\begin{tabular}{lcc}
\hline $\begin{array}{l}\text { Gestational } \\
\text { age (weeks) }\end{array}$ & Number of patients & Percentage \\
\hline$<35$ & 2 & 4.08 \\
$35-36$ & 11 & 22.44 \\
$37-38$ & 27 & 55.1 \\
$39-40$ & 9 & 18.36 \\
\hline
\end{tabular}

Table-VI shows that out of 49 patients, only 05(10.20\%) women had normal vaginal delivery while 44 (89.79\%) women went through LSCS. Indications for cesarean section were fetal distress (14.28\%), previous cesarean section (30.61\%), malpresentation (8.16\%), non-progression of labor (14.28\%) and IUGR (22.44\%).

Table-VI

Mode of Delivery ( $n=49)$

\begin{tabular}{lcc}
\hline Type of delivery & No of patients & (percentage) \\
\hline $\begin{array}{l}\text { Normal vaginal } \\
\text { delivery }\end{array}$ & 05 & $(10.20)$ \\
LUCS & 44 & (89.79) \\
\hline
\end{tabular}

Regarding fetal outcome, the rate of prematurity (55.5\%) were high among class II and class III while in case of class I, out of 40 women, thirty three (82.5\%) delivered at term and seven (17.5\%) delivered at preterm. Mean $( \pm S D)$ neonatal birth weight was average $(2.80 \pm 0.20 \mathrm{~kg})$ in class I, while birth weight was low in class II $(2.30 \pm 0.26 \mathrm{~kg})$ and class III $(2.10 \pm 0.34 \mathrm{~kg})$. No baby was delivered stillborn or there was no neonatal death (Table- VII).

Regarding maternal outcome, 9 women developed heart failure. Among them two patients were of class I, 04 patients of class II and 03 patients of class III. Mean ( \pm SD) hospital stay was $7.50( \pm 1.50)$, $9.50( \pm 1.56)$ and $13.80( \pm 4.2)$ days for patients of class I, class II and class III heart disease respectively. Among the patients, two expired (Table-VIII). One of them, was a case of Eisenmenger's syndrome, was of class III heart disease. The patient died on her $7^{\text {th }}$ post operative day, may be due to pulmonary embolism. The other patient, was a case of congenital heart disease having ASD, VSD with TR, was asymptomatic on admission. She died on her $8^{\text {th }}$ post operative day due to heart failure.

Table-VII

Fetal outcome $(n=49)$

\begin{tabular}{lcccc}
\hline Functional & Term labor & Preterm labor & Stillborn & Birth weight $(\mathrm{kg})$ \\
Classification (NYHA) & $(n=37)$ & $(n=12)$ & & $(\mathrm{n}=49)$ \\
& No. $(\%)$ & No. $(\%)$ & 0 & Mean $( \pm$ SD $)$ \\
\hline Class I $(n=40)$ & $33(82.5)$ & $07(17.5)$ & 0 & $2.80( \pm 0.20)$ \\
Class II $(n=6)$ & $03(50)$ & $03(50)$ & 0 & $2.30( \pm 0.26)$ \\
Class III $(n=3)$ & $01(33.3)$ & $02(66.6)$ & 0 & $2.10( \pm 0.34)$ \\
\hline
\end{tabular}


Table-VIII

Maternal outcome $(n=50)$

\begin{tabular}{lccc}
\hline $\begin{array}{l}\text { Functional } \\
\text { Classification }\end{array}$ & $\begin{array}{c}\text { Heart failure } \\
(\mathrm{n}-9)\end{array}$ & $\begin{array}{c}\text { Hospital stay } \\
\text { (days) }\end{array}$ & $\begin{array}{c}\text { Mortality } \\
(\mathrm{n}=2)\end{array}$ \\
\hline (NYHA) & No. $(\%)$ & Mean $( \pm$ SD) & No. $(\%)$ \\
Class I $(n=40)$ & $02(04)$ & $7.50( \pm 1.50)$ & $01(02)$ \\
Class II $(n=07)$ & $04(08)$ & $9.50( \pm 1.56)$ & $00(00)$ \\
Class III $(n=03)$ & $03(06)$ & $13.80( \pm 4.2)$ & $01(02)$ \\
\hline
\end{tabular}

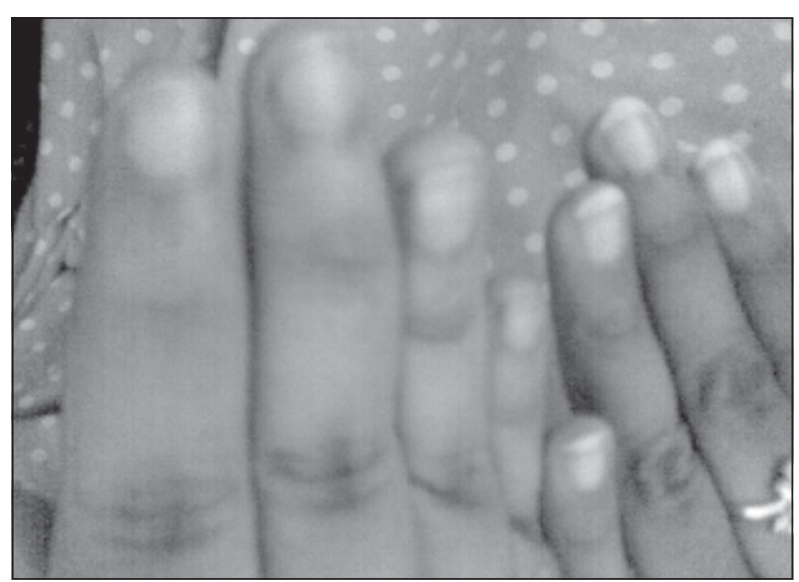

Fig.-1: Drumstick appearance of fingers in a women with Fallot's Tetralogy.

\section{Discussion:}

Cardiac disease in pregnancy is a cause for concern and is an important recognized cause of maternal death. ${ }^{8,9}$ In western countries, a progressive decline has been noticed in the incidence of rheumatic heart disease. However, such a trend has not been noticed in our country.

During the study period (January 2006 to September 2007), fifty patients with heart diseases were admitted in the fetomaternal medicine unit of BSMMU. Among them, 37 (74\%) patients had rheumatic heart disease and in the rheumatic heart disease group, mitral stenosis was the most common lesion (28\%). The rest, $13(26 \%)$ had congenital lesions, of which atrial septal defect was the most common form (16\%).

A study by Karaalp ${ }^{10}$ also showed that majority of the patients with heart disease in pregnancy had rheumatic heart disease (70\%) and most of the rheumatic heart lesions were mitral stenosis. In the study congenital lesion was 30 percent, and atrial septal defect was the most common congenital valvular disease. The findings are similar to this study.
Another study done by Sawhney et al. ${ }^{11}$ showed that rheumatic valvular disease was 68.5 percent and mitral stenosis was the most common rheumatic valvular lesion, and congenital valvular disease was 31.5 percent and atrial septal defect was the most common congenital lesion.

A similar study by McFaul et al. ${ }^{12}$ showed that majority of the cases of heart disease in pregnancy were rheumatic in origin and mitral stenosis was the common lesion. Amongst congenital one, atrial septal defect was the most common form. Hence present study findings are consistent with other study findings.

In this series, out of 50 patients, 13 (26\%) had their lesions surgically corrected before they became pregnant (8 patients with rheumatic heart disease \& 5 with congenital lesions). A study done by Hsich et al. ${ }^{13}$ showed that 27 percent patients had surgically corrected lesions. Another study done by Sawhney et al. ${ }^{14}$ showed $38.6 \%$ patient had undergone surgical correction prior to pregnancy.

In this study, mean ( $\pm S D)$ maternal age was $27.00( \pm 4.2)$ years, parity $1.8 \pm 0.50$ and primigravida was 57.13 percent. Some of the findings are consistent with the study by Sawhney et al. ${ }^{11}$ who found mean $( \pm S D)$ maternal age was $25( \pm 4)$ years, parity $0.7 \pm 0.8$ and primigravida 53 percent.

In this study 80 percent patients were in class I, 14 percent in class II and 6 percent in class III on presentation. In a study by Sawhney et al. ${ }^{11}$ found 95.4 percent in class I and II and 4.8 percent in class III. Another study done by Hameed et al. ${ }^{15}$ showed that $36(55 \%)$ out of 66 patients were in class I, 28 (42\%) in class II and 2 (3\%) in class III on presentation.

Regarding gestational age of the patients during delivery, this study finding shows mean ( $\pm S D$ ) gestational age was $37.50( \pm 2.50)$ weeks. A study by Sawhney et al. ${ }^{11}$ showed mean gestational age was 
$37.8( \pm 3.1)$ weeks, which is also consistent with the findings of the present study.

In this study vaginal delivery was done in only 5 (10.20 $\%)$ patients who went into labor spontaneously and others $44(89.79 \%)$ underwent cesarean section. A study done by Hameed et al. ${ }^{17}$ showed mode of delivery was vaginal in 61 (92\%) out of 66 patients with valvular heart disease and others had cesarean section due to obstetric indications and cardiac lesions. Another study done by Bonow et al. ${ }^{16}$ showed mode of delivery was vaginal in 196 (78.1\%) out of 251 and cesarean section done on 55 (21.9\%) patients. The rate of cesarean delivery was higher in this study compared to others studies. This high rate of cesarean delivery was due to perceived cardiovascular risk for the mother during pregnancy. We did not induce labor in any of the cases due to lack of facilities required for monitoring cardiorespiratory status of the patients during labor and delivery.

Although there were higher incidences of cesarean section in the present study, the perinatal outcome was good compared to other studies in spite of early termination in some cases. This might be due to more patients were booked cases, were on regular antenatal care and were admitted at class I stage of the disease, the birth weight of the babies were average and the neonatal support was also good.

Regarding fetal outcome, the present study showed that live birth rate was $100 \% .12$ patients had preterm delivery, of which 7 were in class I, 3 in class II and 2 in class III. Mean ( \pm SD) birth weight was $2.80( \pm 0.20)$ $\mathrm{kg}$ in class I, 2.30 $( \pm 0.26) \mathrm{kg}$ in class II and 2.10 $( \pm 0.34)$ $\mathrm{kg}$ in class III.

A study done by Sawhney et al. ${ }^{11}$ showed that livebirth were 252 out of 254 patients, and 2 were stillbirths. Mean ( \pm SD) birth weight was 2,648( \pm 539.1$)$ g. Another study done by Hameed et al. ${ }^{17}$ showed that live birth were 64 out of 66 patients and stillbirth were 2. Mean ( $\pm S D$ ) birth weight was $2,897( \pm 838) \mathrm{g}$. Preterm delivery was 15 (23\%) out of 66 .Another study done by Sawhney et al ${ }^{14}$ showed preterm birth rate was $12 \%$. Studies done by Hsich et al. ${ }^{13}$ and Shime et al. ${ }^{18}$ reported higher incidences of preterm birth in patients with valvular heart disease.

Regarding maternal outcome of pregnant patients with valvular heart disease, $40(80.0 \%)$ patients were in class I, 7 (14\%) in class II and $3(6 \%)$ in class III on admission. Heart failure developed in 9 patients, among them 2 patients were in class-I, 4 patients were in class II and 3 patients in class III. This might not have occurred if there were facilities to monitor intravascular volume status in these patients properly. Also there was inadequate ICU facility to deal with these high risk patients. Mean hospital stay was more in class III (13.8 +4.2 days) patients compared to class

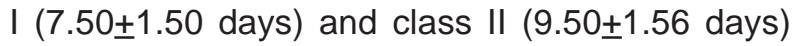
patients. Out of 50 patients, 2 expired. One of them was of class III heart disease, expired during puerperium. She was a case of Eisenmenger's syndrome and died on her $7^{\text {th }}$ post operative day. This patient developed respiratory distress on her $1^{\text {st }} \mathrm{POD}$, and then referred to ICU from where she returned on $6^{\text {th }}$ POD with her condition improved but deteriorated again and died suddenly. The cause of her death was most probably due to pulmonary embolism. Another patient was on class I on admission, was a case of ASD, VSD with TR. She died on her $8^{\text {th }}$ post operative day due to heart failure. This patient developed respiratory distress on her $4^{\text {th }} \mathrm{POD}$, when her cardiac status was again evaluated by cardiologist and $\mathrm{ECHO}$ was done, it showed severe pulmonary hypertension. She received all supportive treatment for heart failure. But her condition gradually deteriorated and she died.

A study done by Hameed et al. ${ }^{15}$ showed that 36 (55\%) out of 66 patients were in class I, $28(42 \%)$ in class II and $2(3 \%)$ in class III on presentation. Heart failure developed in 9 patients, among them 7 patients were in class II and 2 patients in class III. Out of 66 patients, only 1 of class III heart disease expired.

A study done by Presbitero et al. ${ }^{19}$ reported a lower incidence of maternal death and other serious complications in women with class I and II heart disease.

In this study, in both the above mentioned cases of death, pregnancies were contraindicated. Both of them were young primigravid, non-booked cases, who were asked for termination of pregnancy by their obstetricians in early pregnancy. But they opted to continue it, received irregular ANC with no anticoagulant therapy throughout the pregnancy and also in puerperium. There was no fixed cardiologist here in BSMMU, only admission unit used to deal with these high risk patients, so treatment option varied. Again there was no facility for autopsy to detect the exact cause of death. 
Heart disease with pregnancy is a very high risk condition and is associated with considerable morbidity and mortality ratio. The management of these cases should be multidisciplinary to optimize care for these patients throughout pregnancy and in the puerperium and early risk stratification should be done to improve the prognosis of pregnancy in women with heart disease.

\section{References:}

1. Grewal M., Biswas MK., perloff D. Cardiac, Hematologic, Palmonary, Renal and Urinary Tract disorder in Pregnancy, in Decherney $\mathrm{AH}$. and Nathan (Eds), Current Obstetrics \& Gynaecologic Diagnosis and Treatment, $9^{\text {th }}$ Edition, 1991; 387 - 427.

2. Rana S. Heart Disease in Pregnancy, in Ratnam SS, Rao KB, Arulkumarans. (Eds), Obstetrics \& Gynaecology, $2^{\text {nd }}$ Edition, 1999; $48-72$.

3. Dutta DC. Heart Disease in Pregnancy in Konar $\mathrm{H}$ (Eds), Text book of obstetrics, $4^{\text {th }}$ Edition, 1998; 293-298.

4. Siu SC, Cofman JM. Heart disease and pregnancy. Cardio Clin 1998; 573:95.

5. Adam AA. Pregnancy and heart disease. Monthly Bulletin, Cardiovascular Institute of South University, May, 2003.

6. Carnetti M, Elkayam U. The effect of valvular heart disease on maternal and fetal outcome of pregnancy. U Am Coll Cardiol 2001; 37:893-9.

7. Chin P, Raman S, Tham SW, The pregnancy outcome of valvular heart disease. J Obstet Gynaecol Res 1998; 24:267-73.

8. Department of Health and Social Security. Report on confidential enquiry into maternal death in England and Wales, 1979-1981. London: Her Majesty's Stationary Office, 1986.

9. Oakley CM. Cardiovascular disease in pregnancy. Can J Cardiol 1990; 6(Suppl 1B): 3B.
10. Karaalp S. Effect of valvular heart disease on maternal and foetal outcome in pregnancy. J Am Coll Cardiol 2001; 37:893-8.

11. Sawhney H, Suri V, Vasishta K, Gupta N, Devi $\mathrm{K}$, Grover A. Pregnancy and congenital heart disease: maternal and foetal outcome. Aust NJ Obstet Gynaecol 1998; 38:266.

12. McFaul PB, Doman JC, Lamki H, Boyle D. Pregnancy complicated by maternal heart disease: a review of 526 women. J Obstet Gynecol 2001; 26:350.

13. Hsich TT, Chen KC, Soong JH. Outcome of pregnancy in patients with organic heart disease in Taiwan. Asia-Oceania J Obstet Gynaecol 1993; 19:21-7.

14. Sawhney H, Aggarwal N, Sury V, Vasishta K, Sharma Y, Grover A. Maternal and perinatal outcome in rheumatic heart disease. Int J Gynaecol Obstet 2003 Jan;80(1):9-14.

15. Hameed A, Karaalp IS, Tummala PP, Wani OR,Canetti M, Akhter MW, Goodwin M, Zapadinsky N, Elkayam U. The effect of valvular heart disease on maternal and fetal outcome of pregnancy. J Am Coll Cardiol. 2001 Mar 1; 37(3):893-9.

16. Bonow RO, Carabello B. ACC/AHA guidelines for the management of pregnant women with mitral stenosis. Am J Obstet Gynecol 1990;163:37- 40.

17. Hameed A, Al Kasab SM, Sabag T, Al Zaibag M. Management of pregnant women with mitral stenosis during pregnancy and puerperium. Arq Bras Cardiol 1992; 58:359-64.

18. Shime J, Mocarski EJM, Hastings D, Webb GD, Mclaughlin PR. Congenital heart disease in pregnancy: short and long term implications. Am J obstet Gynecol 1987; 156:313-22.

19. Presbitero P, Somerville J, Stone S, Aruta E, Spiegelhalter $\mathrm{P}$, Rabajolo $\mathrm{F}$. Pregnancy in cyanotic congenital heart disease. Circulation 1994; 89:2673-6. 